Jeffrey E. Ming • Michelle E. Kaupas · Erich Roessler

Han G. Brunner • Mahin Golabi • Mustafa Tekin

Robert F. Stratton · Eva Sujansky • Sherri J. Bale

Maximilian Muenke

\title{
Mutations in PATCHED-1, the receptor for SONIC HEDGEHOG, are associated with holoprosencephaly
}

Received: 13 December 2001 / Accepted: 6 January 2002 / Published online: 2 March 2002

(C) Springer-Verlag 2002

\begin{abstract}
Holoprosencephaly (HPE) is the most commonly occurring congenital structural forebrain anomaly in humans. HPE is associated with mental retardation and craniofacial malformations. The genetic causes of HPE have recently begun to be identified, and we have previously shown that HPE can be caused by haploinsufficiency for SONIC HEDGEHOG (SHH). We hypothesize that mutations in genes encoding other components of the $\mathrm{SHH}$ signaling pathway could also be associated with HPE.
\end{abstract}

\footnotetext{
J.E. Ming $\cdot$ M. Muenke

Division of Human Genetics,

Departments of Pediatrics and Genetics,

Children's Hospital of Philadelphia,

University of Pennsylvania School of Medicine, Philadelphia,

Pennsylvania, USA
}

M.E. Kaupas · M. Muenke

Division of Neurology, Departments of Pediatrics and Genetics,

Children's Hospital of Philadelphia,

University of Pennsylvania School of Medicine, Philadelphia,

Pennsylvania, USA

E. Roessler $\cdot$ M. Muenke (凶)

Medical Genetics Branch,

National Human Genome Research Institute,

National Institutes of Health, 10 Center Drive, MSC 1852,

Building 10, 10C103, Bethesda, MD 20892-1852, USA

e-mail: muenke@nih.gov,

Tel.: +1-301-4028167, Fax: +1-301-4807876

H.G. Brunner

University of Nijmegen, Nijmegen, The Netherlands

M. Golabi

University of California, San Francisco, California, USA

M. Tekin

Medical College of Virginia, Richmond, Virginia, USA

R.F. Stratton

University of Texas Health Science Center,

San Antonio, Texas, USA

E. Sujansky

Children's Hospital, Denver, Colorado, USA

S.J. Bale

NIAMS, NIH, Bethesda, Maryland, USA
PATCHED-1 (PTCH), the receptor for SHH, normally acts to repress SHH signaling. This repression is relieved when SHH binds to PTCH. We analyzed PTCH as a candidate gene for HPE. Four different mutations in $P T C H$ were detected in five unrelated affected individuals. We predict that by enhancing the repressive activity of $\mathrm{PTCH}$ on the SHH pathway, these mutations cause decreased SHH signaling, and HPE results. The mutations could affect the ability of PTCH to bind SHH or perturb the intracellular interactions of PTCH with other proteins involved in SHH signaling. These findings further demonstrate the genetic heterogeneity associated with HPE, as well as showing that mutations in different components of a single signaling pathway can result in the same clinical condition.

\section{Introduction}

Holoprosencephaly (HPE) is the most common congenital forebrain anomaly in humans. It is characterized by a failure of complete separation of the forebrain into distinct right and left halves. Thus, there may be incomplete separation of the cerebral hemispheres, thalami, and lateral ventricles. While the live-birth prevalence is estimated at 1 in 10,000 infants, it may occur as frequently as 1 in 250 conceptuses (Croen et al. 1996; Matsunaga and Shiota 1977). HPE is associated with mental retardation and striking craniofacial anomalies, including cyclopia, ocular hypotelorism, nose anomalies, and cleft lip/palate (Muenke and Beachy 2001). The condition is etiologically very heterogeneous, and a number of genetic defects and environmental exposures are causally associated with HPE. Although HPE usually occurs sporadically, it can also be transmitted in an autosomal dominant fashion. Haploinsufficiency for SONIC HEDGEHOG (SHH) can cause human HPE (Roessler et al. 1996, 1997). Mutations in $S H H$ are the most common identified cause of both autosomal dominant and sporadic HPE (Nanni et al. 1999). We hypothesized that mutations in genes encoding other components of the SHH pathway could also cause HPE. 
Patched-1 (Ptch), the multipass transmembrane receptor for Shh (Chen and Struhl 1996; Marigo et al. 1996; Stone et al. 1996), acts to repress Shh signaling in the absence of ligand. Upon binding of Shh, the repressive activity of Ptch is relieved, and the Shh signaling pathway is activated. Haploinsufficiency for PTCH has been shown to cause the nevoid basal cell carcinoma syndrome (Gorlin syndrome) (Hahn et al. 1996; Johnson et al. 1996). Mutations leading to loss of PTCH function have also been identified in sporadic basal cell carcinomas and a number of other tumors (reviewed by Saldanha 2001). Loss of Ptch leads to increased Shh signaling activity (Goodrich et al. 1997). In contrast to the conditions resulting from loss of PTCH function (and subsequent constitutive activation of the SHH pathway), we hypothesized that mutations in $P T C H$ resulting in a gain of repressive function would mimic loss of SHH activity and cause HPE. Thus, we expect $P T C H$ mutations that cause HPE will result in missense mutations that lead to enhanced repressive activity of PTCH on the SHH pathway. In this study, we performed mutation analysis of $P T C H$ in both familial and sporadic HPE cases.

\section{Materials and methods}

Patient samples

All of the patients were evaluated by a clinical geneticist prior to enrollment in the study. All patients had a normal karyotype. The genomic DNA from HPE patients and family members (when available) was extracted from lymphocytes or established lymphoblastoid cell lines by routine methods. All samples were obtained by informed consent according to the guidelines of our institutional review board.

PCR methods, single strand conformational polymorphism (SSCP) analysis, and sequencing

Human $P T C H$ is composed of 23 exons. Utilizing previously described primer sets (Hahn et al. 1996; Xie et al. 1997), we PCR-amplified the complete coding region and exon-intron boundaries of PTCH in 100 unrelated patients with HPE. We used 25 pairs of primers (two overlapping amplicons were generated for exons 13 and 23) and the published conditions to perform the mutation analysis. The PCR reactions were carried out in a Perkin-Elmer thermal cycler.

Single strand conformational polymorphism (SSCP) analysis was performed as previously described (Nanni et al. 1999). Products demonstrating a band-shift were purified and subjected to DNA sequence analysis by the Nucleic Acid and Protein Core Facility of the Children's Hospital of Philadelphia on an ABI Prism 377 analyzer. Exons in which nucleotide changes were detected that resulted in an amino acid substitution were assayed for mutations in over 200 control chromosomes from unrelated normal individuals.

\section{Nomenclature}

Gene mutation nomenclature used in this article follows the recommendations of den Dunnen and Antonarakis (2001). Gene symbols used in this article follow the recommendations of the HUGO Gene Nomenclature Committee (Povey et al. 2001)
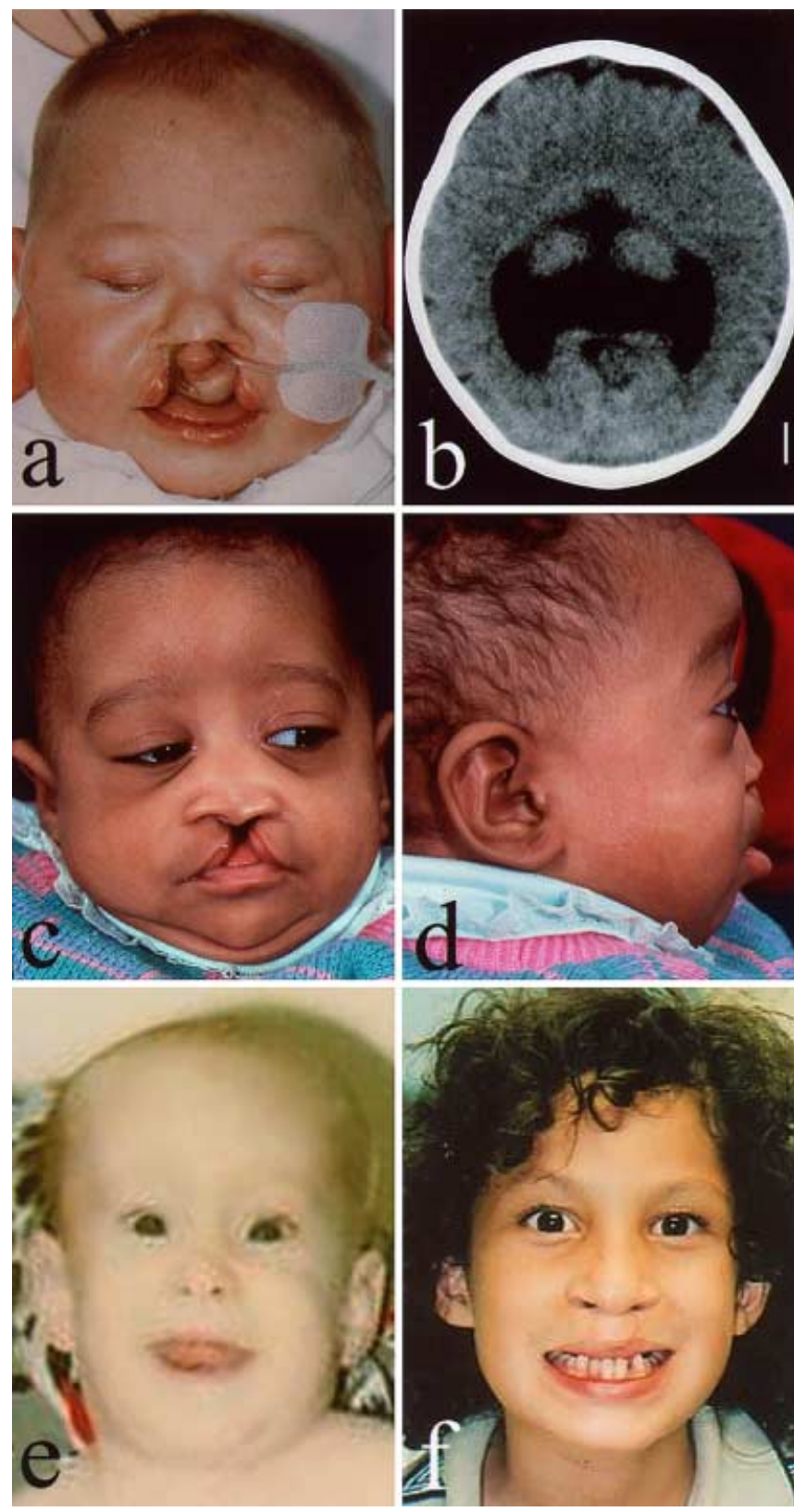

Fig. 1 Patient 180 (PTCH A393T) with bilateral cleft lip and palate (a), and semilobar HPE on cranial CT (b). Additional findings include hypopituitarism, absent anterior and partly absent posterior interhemispheric fissure, continuity of the frontal lobe including continuous gyri across the midline, a midline ventricle with a single frontal horn but partial separation of the posterior horns, and at least partial separation of the parietal and occipital lobes (white bar $=1 \mathrm{~cm}$ ). c, d Frontal and lateral facial views of patient 329 (PTCH T728M) with severe midfacial hypoplasia including midline cleft of the lip and palate. e Patient 83 (PTCH T1052M) with macrocephaly due to alobar HPE and hydrocephalus. Facial findings include hypotelorism and upward slanting palpebral fissures. f Brother of patient 1335 , both of whom carry the PTCH T728M mutation. Note the repaired bilateral cleft of the lip 
Table $1 P T C H$ mutations detected in patients with HPE

\begin{tabular}{lclll}
\hline Mutation no. & Patient no. & Mutation & Effect & Location in protein \\
\hline 1 & 180 & $1165 \mathrm{G}>\mathrm{A}$ & A393T & Extracellular loop \\
2 & 329 & $2171 \mathrm{C}>\mathrm{T}$ & T728M & Intracellular loop \\
& 1335 & $2171 \mathrm{C}>\mathrm{T}$ & T728M & Intracellular loop \\
3 & 775 & $2471 \mathrm{~A}>\mathrm{G}$ & S827G & Extracellular loop \\
4 & 83 & $3143 \mathrm{C}>\mathrm{T}$ & T1052M & Intracellular loop \\
\hline
\end{tabular}

\section{Results}

We analyzed the complete coding sequence and intronexon boundaries of $P T C H$ in DNA samples derived from 100 probands with HPE. We detected four different missense mutations in five unrelated individuals with HPE (Fig. 1, Table 1). The first mutation (1165G $>$ A) predicted a substitution of a threonine for an alanine (A393T), and was present in an affected female (patient 180 in Table 1, Fig. 1a, b) and her clinically normal father. The second mutation $(2171 \mathrm{C}>\mathrm{T}, \mathrm{T} 728 \mathrm{M})$ was present in two unrelated probands. In the first pedigree, the mutation was present in a girl with semilobar HPE, absence of the corpus callosum, and fusion of the thalami (patient 1335 in Table 1). Her brother has a single central maxillary incisor, bilateral cleft lip/palate, and developmental delay (Fig. 2f). Their clinically normal mother did not carry the mutation, and their father was not available for testing. In the second pedigree, the mutation was present in a female with HPE and partial agenesis of the corpus callosum, panhypopituitarism, midline cleft lip and palate, a small omphalocele, and mild to moderate developmental delay (patient 329 in Table 1, Fig. 1c, d). Her phenotypically normal mother did not have the mutation, and the girl's father was not available for testing.

The third mutation $(2471 \mathrm{~A}>\mathrm{G}, \mathrm{S} 827 \mathrm{G})$ was present in a female with HPE, seizures, and bilateral cleft lip, and in her clinically normal mother. The fourth mutation $(3143 \mathrm{C}>\mathrm{T}$, T1052M) was detected in a male with alobar HPE and hypotelorism (patient 83 in Table 1, Fig. 1e) and in his brother with hypotelorism and developmental delay. Their clinically normal father also carried the mutation. Their sister and mother, both of whom have normal cognitive development, did not carry the mutation.

All of the affected amino acids are conserved in both the chick and mouse orthologs of PTCH. These mutations were not detected in over 200 normal control chromosomes and have not been reported in the screening for PTCH mutations in conditions associated with loss of PTCH activity (basal cell carcinomas, Gorlin syndrome, and other tumors) (830 patients/tumors screened in the 31 reports reviewed) (reviewed by Saldanha 2001 and others). Thus, the mutations detected in the HPE patients are unlikely to be rare polymorphisms.

In addition, we identified 24 other nucleotide changes that are likely to be polymorphisms without functional significance. These nucleotide changes either occurred in an intronic sequence, were not predicted to result in an amino acid substitution, did not segregate with the pheno-

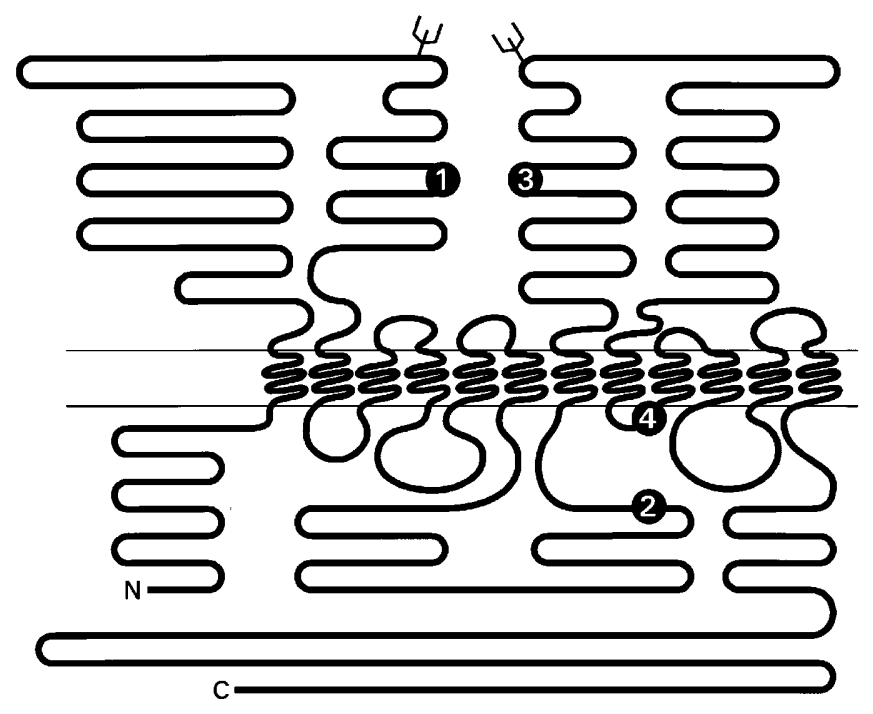

Fig. 2 Model of the PTCH protein. The predicted position of the four mutations (1: A393T; 2: T728M; 3: S827G; 4: T1052M; as numbered in Table 1), is indicated

type in familial cases, and/or were found in the normal control population (data not shown).

\section{Discussion}

We detected four different mutations in five unrelated pedigrees with HPE. Since the constitutive activity of PTCH is to repress the SHH pathway, we expected that a mutation which causes a gain of repressive function of $\mathrm{PTCH}$ would mimic loss of SHH activity, and lead to HPE. Thus, we anticipated that the PTCH mutations would result in missense mutations affecting discrete functional regions of the predicted PTCH protein (Goodrich et al. 1996). Two of the detected mutations $(1165 \mathrm{G}>\mathrm{A}, 2471 \mathrm{~A}>\mathrm{G})$ would be expected to reside in the large extracellular loops that may act to bind SHH (Marigo et al. 1996) (Fig. 2). We expect that these two mutations affect the ability of PTCH to bind $\mathrm{SHH}$. In this case, even if SHH is present, if PTCH cannot bind the SHH, the signal will not be transmitted. Deletion of one of these extracellular loops was shown in a mouse model to result in a PTCH protein that suppressed SHH signal transduction and did not respond to $\mathrm{SHH}$ protein (Briscoe et al. 2001).

Two additional mutations $(2171 \mathrm{C}>\mathrm{T}, 3143 \mathrm{C}>\mathrm{T})$ are expected to affect amino acids that are in adjacent intracellular loops. Although these amino acids are separated by 
some distance in the primary amino acid sequence and cDNA sequence, in the PTCH protein the affected amino acids lie in adjacent intracellular loops and may in fact lie in close proximity to each other in the cell (Fig. 2). We suspect that these residues are normally involved in converting PTCH to an inactive state when SHH is present, thus relieving the repression of the SHH pathway and allowing SHH signaling to proceed. We predict that these mutations could perturb interactions of the intracellular domains of PTCH with Smoothened or other proteins involved in SHH signal transduction. This could alter responsiveness of PTCH to the SHH signal such that the repressive activity of PTCH is maintained even in the presence of SHH. These mutations could yield information regarding functional domains of the PTCH protein. Studies examining the functional effect of these mutations will be required to confirm that these mutations alter responsiveness to $\mathrm{SHH}$ and are being pursued.

The finding of $P T C H$ mutations in clinically normal individuals in the HPE pedigrees is consistent with the phenotype described in pedigree analysis of autosomal dominant HPE, including kindreds with $S H H$ mutations. It is estimated that approximately one-third of obligate carriers of autosomal dominant forms of HPE are asymptomatic with normal cognitive function (Cohen 1989). In addition, SHH mutations have been detected in probands with HPE that were also present in clinically normal members of the same kindred that are obligate carriers of the defective HPE gene (Roessler et al. 1996). Similar to the patients with mutations in $S H H$, craniofacial anomalies were present in patients with $P T C H$ mutations. There are no clinical features that distinguish the individuals with $P T C H$ mutations compared to the HPE population as a whole or those with identified $\mathrm{SHH}$ mutations.

Animal models also support the concept that mutations resulting in enhanced PTCH activity can cause HPE. A proportion of mice with increased Ptch activity driven by the nestin enhancer showed fusion of the lateral ventricles, consistent with HPE (Goodrich et al. 1999). This finding is similar to the phenotype of null mutant mice for Shh, which show HPE and cyclopia (Chiang et al. 1996). Both the Shh and Ptch mutant mice show similar cellular defects in specification of ventral cell types in the neural tube.

The identification of $P T C H$ mutations in patients with HPE demonstrates that alterations in two components of the same signaling pathway that are expected to lead to decreased SHH signaling can result in the same clinical phenotype, HPE. This concept is also supported in animal models of HPE. In addition to the finding of HPE in Shh and Ptch mutant mice, homozygous null mutant mice for the gene $S m o$, which encodes the transmembrane protein Smoothened that is involved in Shh signaling, have cyclopia and holoprosencephaly (Zhang et al. 2001). Null mutant mice for Gli2, which encodes a transcription factor that regulates expression of SHH target genes, show a single central maxillary incisor (Hardcastle et al. 1998), which is a microform of human HPE. Interestingly, mutations in several components of the SHH pathway that lead to increased SHH signaling can all lead to skin tumors with characteristics of basal cell carcinomas in humans and animal models (Dahmane et al. 1997; Fan et al. 1997; Grachtchouk et al. 2000; Oro et al. 1997). Overall, these data demonstrate that mutations in different components of the Shh pathway that lead to a common effect on Shh signaling can each result in the same phenotype: decreased Shh activity causing HPE, and increased Shh activity causing tumors.

Based on the mouse model, we suspect that the $P T C H$ mutations cause abnormal dorsal-ventral patterning of the forebrain. There are multiple lines of evidence indicating that loss of normal ventral specification in the forebrain can result in HPE. Homozygous null mutant mice for $S h h$ show HPE and loss of ventral cell types in the forebrain (Chiang et al. 1996). In addition to HPE-like features, mice with increased Ptch activity have dorsal-ventral patterning defects in the neural tube (Goodrich et al. 1999). Similarly, loss of the ventrally-expressed transcription factor Nkx2.1 in the mouse can lead to abnormal dorsalventral specification of the forebrain (Sussel et al. 1999) and midline fusion of forebrain structures (Kimura et al. 1996). In addition, ectopic expression of the bone morphogenetic proteins, which mediate dorsal induction, can also cause HPE in a chick model (Golden et al. 1999). Exposure to ectopic bone morphogenetic protein caused loss of ventral cells, possibly mediated by increased cell death. Thus, there are a number of animal models indicating that HPE may be caused by defects in dorsal-ventral patterning. The hypothesized increased activity of PTCH conferred by the identified mutations would be expected to cause loss of ventral cell types in the developing forebrain, resulting in HPE. We predict that alterations in the activity of other proteins that regulate this process, including other components of the SHH signaling pathway, could also result in HPE.

Acknowledgements We are grateful to the families for their participation this study. We thank Dr. W.B. Dobyns for reading the cranial CTs. This work was supported in part by NIH grants HD01218 (to J.E.M.), HD29862 (to M.M.) and by the Division of Intramural Research, NHGRI, NIH (to M.M.).

\section{References}

Briscoe J, Chen Y, Jessell TM, Struhl G (2001) A hedgehog-insensitive form of patched provides evidence for direct longrange morphogen activity of sonic hedgehog in the neural tube. Mol Cell 7:1279-1291

Chen Y, Struhl G (1996) Dual roles for patched in sequestering and transducing Hedgehog. Cell 87:553-563

Chiang C, Litingtung Y, Lee E, Young K, Corden J, Westphal H, Beachy P (1996) Cyclopia and defective axial patterning in mice lacking Sonic Hedgehog gene function. Nature 383:407413

Cohen MM Jr (1989) Perspectives on holoprosencephaly: Part I. Epidemiology, genetics, and syndromology. Teratology 40: 211-235

Croen LA, Shaw GM, Lammer EJ (1996) Holoprosencephaly: epidemiologic and clinical characteristics of a California population. Am J Med Genet 64:465-472 
Dahmane N, Lee J, Robins P, Heller P, Ruiz i Altaba A (1997) Activation of the transcription factor Gli1 and the Sonic Hedgehog signalling pathway in skin tumours. Nature 389:876-881

den Dunnen JT, Antonarakis SE (2001) Nomenclature for the description of human sequence variations. Hum Genet 109:121124

Fan H, Oro AE, Scott MP, Khavari PA (1997) Induction of basal cell carcinoma features in transgenic human skin expressing Sonic Hedgehog. Nat Med 3:788-792

Golden J, Bracilovic A, McFadden K, Beesley J, Rubenstein J, Grinspan J (1999) Ectopic bone morphogenetic proteins 5 and 4 in the chicken forebrain leads to cyclopia and holoprosencephaly. Proc Natl Acad Sci USA 96:2439-2444

Goodrich LV, Johnson RL, Milenkovic L, McMahon JA, Scott MP (1996) Conservation of the hedgehog/patched signaling pathway from flies to mice: induction of a mouse Patched gene by Hedgehog. Genes Dev 10:301-312

Goodrich LV, Milenkovic L, Higgins KM, Scott MP (1997) Altered neural cell fates and medulloblastoma in mouse patched mutants. Science 277:1109-1113

Goodrich LV, Jung D, Higgins KM, Scott MP (1999) Overexpression of Ptc1 inhibits induction of Shh target genes and prevents normal patterning in the neural tube. Dev Biol 211:323-334

Grachtchouk M, Mo R, Yu S, Zhang X, Sasaki H, Hui CC, Dlugosz AA (2000) Basal cell carcinomas in mice overexpressing Gli2 in skin. Nat Genet 24:216-217

Hahn H, Wicking C, Zaphiropoulous PG, Gailani MR, Shanley S, Chidambaram A, Vorechovsky I, Holmberg E, Unden AB, Gillies S, Negus K, Smyth I, Pressman C, Leffell DJ, Gerrard B, Goldstein AM, Dean M, Toftgard R, Chenevix-Trench G, Wainwright B, Bale AE (1996) Mutations of the human homolog of Drosophila Patched in the nevoid basal cell carcinoma syndrome. Cell 85:841-851

Hardcastle Z, Mo R, Hui CC, Sharpe PT (1998) The Shh signalling pathway in tooth development: defects in Gli2 and Gli3 mutants. Development 125:2803-2811

Johnson RL, Rothman AL, Xie J, Goodrich LV, Bare JW, Bonifas JM, Quinn AG, Myers RM, Cox DR, Epstein EH, Scott MP (1996) Human homolog of patched, a candidate gene for the basal cell nevus syndrome. Science 272:1668-1671

Kimura S, Hara Y, Pineau T, Fernandez-Salguero P, Fox CH, Ward JM, Gonzalez FJ (1996) The T/ebp null mouse: thyroidspecific enhancer-binding protein is essential for the organogenesis of the thyroid, lung, ventral forebrain, and pituitary. Genes Dev 10:60-69

Marigo V, Davey RA, Zuo Y, Cunningham JM, Tabin CJ (1996) Biochemical evidence that Patched is the Hedgehog receptor. Nature 384:176-179
Matsunaga E, Shiota K (1977) Holoprosencephaly in human embryos: epidemiologic studies of 150 cases. Teratology 16:26172

Muenke M, Beachy PA (2001) Holoprosencephaly. In: Scriver CR, Beaudet A, Valle D, Sly WS (eds) The metabolic and molecular basis of inherited disease, 8th edn. McGraw-Hill, New York, pp 6203-6230

Nanni L, Ming JE, Bocian M, Steinhaus K, Bianchi DW, DieSmulders C, Giannotti A, Imaizumi K, Jones KL, Campo MD, Martin RA, Meinecke P, Pierpont ME, Robin NH, Young ID, Roessler E, Muenke M (1999) The mutational spectrum of the Sonic Hedgehog gene in holoprosencephaly: SHH mutations cause a significant proportion of autosomal dominant holoprosencephaly. Hum Mol Genet 8: 2479-2488

Oro AE, Higgins KM, Hu Z, Bonifas JM, Epstein EH, Scott MP (1997) Basal cell carcinomas in mice overexpressing Sonic Hedgehog. Science 276:817-821

Povey S, Lovering R, Bruford E, Wright M, Lush M, Wain H (2001) The HUGO Gene Nomenclature Committee (HGNC). Hum Genet DOI 10.1007/s00439-001-0615-0

Roessler E, Belloni E, Gaudenz K, Jay P, Berta P, Scherer S, Tsui L-C, Muenke M (1996) Mutations in the human Sonic Hedgehog gene cause holoprosencephaly. Nat Genet 14:357-360

Roessler E, Belloni E, Gaudenz K, Vargas F, Scherer SW, Tsui LC, Muenke M (1997) Mutations in the C-terminal domain of Sonic Hedgehog cause holoprosencephaly. Hum Mol Genet 6: $1847-1853$

Saldanha G (2001) The Hedgehog signalling pathway and cancer. J Pathol 193:427-432

Stone DM, Hynes M, Armanini M, Swanson TA, Gu Q, Johnson RL, Scott MP, Pennica D, Goddard A, Phillips H, Noll M, Hooper JE, de Sauvage F, Rosenthal A (1996) The tumoursuppressor gene Patched encodes a candidate receptor for Sonic Hedgehog. Nature 384:129-134

Sussel L, Marin O, Kimura S, Rubenstein JL (1999) Loss of Nkx2.1 homeobox gene function results in a ventral to dorsal molecular respecification within the basal telencephalon: evidence for a transformation of the pallidum into the striatum. Development 126:3359-3370

Xie J, Johnson RL, Zhang X, Bare JW, Waldman FM, Cogen PH, Menon AG, Warren RS, Chen LC, Scott MP, Epstein EH (1997) Mutations of the PATCHED gene in several types of sporadic extracutaneous tumors. Cancer Res 57:2369-2372

Zhang XM, Ramalho-Santos M, McMahon AP (2001) Smoothened mutants reveal redundant roles for Shh and Ihh signaling including regulation of $1 / \mathrm{r}$ asymmetry by the mouse node. Cell 105:781-792 